

\section{INDICE}

EDITORIAL PERSONAL ÁMBITOS

Apresentação do monográfico. Abordagem qualitativa: olhares e práticas transdisciplinares nas ciências antropossociais

Presentation of the monograph. Qualitative approach: transdisciplinary views and practices in anthroposocial sciences

Ronaldo Nunes Linhares, António Pedro Costa

MONOGRAFICOS MONOGRAPHS

Identidades femininas na rede: as crianças falam!

Female identities on line: children can speak

Marta Maria Azevedo Queiroz

$12-31$

Transição de cuidados de enfermagem: ISBAR na promoção da segurança dos

doentes - revisão scoping

Transition of nursing care: ISBAR in promoting patient safety - scoping review

Ana Rita Esteves Figueiredo, Teresa Maria Ferreira dos Santos Potra, Pedro Ricardo Martins Bernardes Lucas

$32-48$

Integración de elementos cualitativos y cuantitativos en metodología observacional

Integration of qualitative and quantitative elements in observational methodology

M. Teresa Anguera, Angel Blanco-Villaseñor, José Luis Losada, Pedro Sánchez-Algarra

49-70

Atos educativos com oficines de ecografias: uma investigação otobiográfica

Educational acts at echographie's cineliers: an otobiographic research

Silas Borges Monteiro, Anaise Avila Severo

Actuación de las políticas: política como texto y política como discurso

Action of policies: policy as text and policy as discourse

Mónica Rocío Barón

88-104 


\section{ÁMBITOS PERSONALES PERSONAL ÁMBITOS}

Un retrato de la cultura local a través del Periodismo cultural. Análisis comparado de Sevilla y Porto Alegre

A portrait of the local culture through cultural Journalism. Comparative analysis of Seville and Porto Alegre

\section{ARTÍCULOS ARTICLES}

Microsociología del profesor universitario

Microsociology of an university professor

Antonio Fernández Vicente

La pobreza y el discurso de los mass media. Un estudio de la prensa local argentina

Poverty and mass media 's discourse. A study of the Argentine local press

María del Rosario Sanchez, Silvia London

La comunicación no verbal en las elecciones andaluzas de 2018. Comparativa de Susana Díaz y Teresa Rodríguez en el debate de RTVE

Non-verbal communication in the Andalusian municipal elections of 2018. Comparison of Susana Díaz and Teresa Rodríguez in the electoral RTVE debate

María Hernández Herrarte, Patricia Zamora-Martínez

El infoentretenimiento en la televisión de pago, Movistar+ y el canal \#0.

El uso transmedia de sus contenidos de humor

Infotainment on pay television, Movistar+ and channel \# 0 . The transmedia use of its humorous content

Metodología y formación docente cuestiones claves para la integración de las TIC en la educación

Methodology and teacher training as a key issue for ICTs integration in Education 


\section{RESEÑAS REVIEWS}

Aquelarre. Mujeres en la cultura de masas

Coven. Women in mass culture

Regla Ismaray Cabreja Piedra

216-220

Transición ecosocial y principios éticos en el periodismo: una guía para la comunicación de nuevas narrativas

The Eco-social transition and ethical principles in journalism: a guide for the communication of new narratives

Amanda Salazar Torres

Narrativas ecofeministas y mapa de transición ecosocial para medios de comunicación Eco-feminist narratives and ecosocial transition map for the media 


\title{
Atos educativos com oficines de ecografias: uma investigação otobiográfica
}

\author{
Educational acts at echographie's cineliers: an otobiographic
}

research

\author{
Dr. Silas Borges Monteiro, Universidade Federal do Mato Grosso, R. Quarenta e \\ Nove, 2367 - Boa Esperança, Cuiabá - MT, 78060-900, Brasil. \\ silasmonteiro@ufmt | Orcid: https://orcid.org/ 0000-0002-6130-920X
}

\begin{abstract}
Anaise Avila Severo, Universidade Federal do Mato Grosso. R. Quarenta e Nove, 2367 - Boa Esperança, Cuiabá - MT, 78060-900, Brasil. anaiseasevero@gmail.com | Orcid: https://orcid.org/ 0000-0002-2715-139X
\end{abstract}

DOI: https://dx.doi.org/10.12795/Ambitos.2020.i49.05

\begin{abstract}
Resumo
Este artigo apresenta resultados parciais de uma investigação desenvolvida no Brasil, na UFMT. A pesquisa fora realizada com estudantes do Ensino Médio em uma escola pública e outra privada confessional. Toma-se como referência o projeto filosófico elaborado por Jacques Derrida para estabelecer o que se denomina como investigação otobiográfica. Como conceito-método fundante, a investigação otobiográfica assume o limiar da vida-obra, vivências-escrituras. O afastamento entre vida e texto, comumente relacionado à experiência escolar, resulta em uma escrita encomendada pelas instâncias institucionais de controle, seja na figura do professor ou mesmo na do Estado avaliador. Embora tais produções atendam aos critérios públicos de escrita e composição, tal prática predominante cede a um discurso hegemônico pré-fabricado, dissolvendo, assim, a escritura como ato de criação e inscrição: a hipótese da pesquisa é de que projeção de filmes-conceitos, com
\end{abstract}


narrativas não-lineares, podem criar espaços de escritura, constituindo um ato educativo. Para este trabalho foram analisadas 88 produções textuais de estudantes de ambas as escolas participantes, a partir do curta-metragem Alike - uma animação dirigida por Daniel Martínez Lara e Rafa Cano Méndez. Tais textos foram produzidos no que denominamos de Oficinas Cinemáticas de Ecografias (OCiE), viabilizadas por meio das formulações de Jacques Aumont (acerca do cinema, filme e teoria) e de Sandra Corazza com as Oficinas de Transcriação (OsT), como estratégia para investigação otobiográfica. A análise foi desenvolvida em três níveis, aqui denominados: heteronimia do estado, autonomia crítica e economia dos signos; a hipótese da pesquisa foi confirmada.

\section{Abstract}

The paper presents partial results of a research fulfilled in UFMT, Brasil. That research had been conducted to high school students from a public and a private school. Has been taken as reference the Jacques Derrida's philosophical project, here called otobiographical investigation. As a founding concept-method, the otobiographical investigation assumes the threshold of life-work, scripture-experiences. The distance between life and text, commonly related to school experience, results in a writing commissioned by the institutional instances of control, whether in the figure of the teacher or even in the evaluating state. Although such productions meet the public criteria of writing and composition, such prevailing practice yields to a prefabricated hegemonic discourse, thus dissolving writing as an act of creation and inscription: the research hypothesis is that projection of concept films, with nonlinear narratives, they can create writing spaces, constituting an educational act. It had analyzed 88 texts of students from both participating schools, writing after short film Alike - an animation directed by Daniel Martínez Lara and Rafa Cano Méndez. These texts were elaborated at Kinematic Echography Ateliers, made possible through the formulations of Jacques Aumont (about cinema, film and theory) and Sandra Corazza with the Transcreation Workshops, as a strategy for otobiographic research. The analysis was developed at three levels, here named: state heteronomy, critical autonomy and sign economy; The research hypothesis was confirmed.

Palavras-chave: educação, otobiografia, escrileitura, didática

Keywords: education, otobiographie, reading-writing, didatic

\section{UMA BREVE APRESENTAÇÃO}

Este trabalho apresenta alguns elementos oriundos de pesquisa financiada pelo Conselho Nacional de Desenvolvimento Científico e Tecnológico (CNPq) intitulada: Pode um filme-conceito ser um ato educativo? Criação de leitura e espectatura, texto e imagem, escritura e cinema. Desenvolvida pelo Grupo de Pesquisa Estudos de 
Filosofia e Formação (EFF), do Instituto de Educação da Universidade Federal de Mato Grosso, no Brasil, a pesquisa, que teve duração de três anos (entre 2017-2020), propõe a apresentação de curtas-metragens com o objetivo de convidar os espectadores a assumirem uma posição de espectatura. O critério de escolha dos curtas fora baseado a favor da não linearidade das narrativas conduzidas pelos diretores. Este tipo de produção cinematográfica opera como dispositivo no qual os espectadores tornam-se participantes ativos na possibilidade de exercitarem a criação de sentido a partir do enredo. Tais curtas, a partir das características postuladas, fomentaram sua conceituação no projeto como filme-conceito.

Para tanto, tais filmes-conceito foram apresentados durante as Oficinas Cinemáticas (OfiCines). Estes espaços correspondem a situações concretas em instituições de ensino, aproximando-se da experiência didática, para operar as oficinas em espaços formais de educação. Nessa via, as OfiCines tratadas nesta pesquisa correspondem a um recorte: realizadas em duas escolas de Cuiabá (capital de Mato Grosso, Brasil) com estudantes concluintes do Ensino Médio em uma escola pública estadual e uma escola privada confessional. Tais distinções poderão ser adiante percebidas a partir da conceituação e dos elementos escolhidos para mapear tais atos educativos enquanto expressões presentes na formação. Vale ressaltar que, neste recorte, a grande maioria dos estudantes ficara situado entre dezesseis à dezoito anos - tal idade corresponde ao período comum para a integralização da Educação Básica no país.

Ainda, a pesquisa desenvolvida pelo financiamento da CNPq buscara empreender como os limites discursivos forneciam potências aos atos educativos. Nesta ocasião, buscamos operar postulações com o ensejo de compreender por meio de quais princípios, generalidades ou, mesmo, por meio de quais critérios os estudantes participantes trataram o filme-conceito. Com tal perspectiva ensaiada, algumas questões foram elaboradas ainda em fase inicial — dado, também, a não conclusão do Projeto $\mathrm{CNPq}$ até à data para o 8ํㅡㄹ Congresso Ibero-Americano em Investigação Qualitativa (CIAIQ), realizado em Lisboa, Portugal, com trabalho intitulado Investigação otobiográfica em criações de leitura e espectatura1.

Se algumas respostas foram testadas, a partir de questões que discorriam acerca da elaboração de quais elementos formativos possibilitaram tratar o filme-conceito enquanto um ato educativo, entendemos que se faz necessário compreender o que norteia a espectatura tal como um dos elementos deste processo. Ainda, buscamos discorrer como, a partir da disseminação de sentido de uma experiência cinematográfica espectral (cf. Derrida, 2012), um ato educativo envolve a questão da espectatura conceituado por Jacques Aumont (2008) e experenciada nos espaços sociais desviados que envolvem as OfiCines por meio do operador otobiográfico para analisar as Oficines de Ecografias. Fora adotado como procedimento de análise das produções neste contexto três movimentos de lei (nómos2) intitulados: Heteronomia do Estado, Autonomia Crítica e, por fim, Economia dos Signos. Enquanto procedimentos 
teórico-metodológicos para a conceituação em torno da analítica, aqui adotada, dos textos escriturados pelos estudantes, tomou-se, ainda, a escritura como um jogo imprescindível à prática de disseminação.

\section{ESPECTATURA E COMUNICAÇÃO}

Para estabelecer a problemática deste trabalho é necessário, ao nosso juízo, uma palavra em torno do que compete ao termo comunicação. Se, no entendimento comum, a comunicação funciona como transporte de sentido de um emissor a um receptor, ainda que leve em consideração toda a complexidade que a isso designa, com as nuances dos limites da emissão, da recepção, dos ruídos, da necessidade do contexto e afins, este trabalho busca deslocar tal perspectiva. Com Derrida (1991), entendemos que o conceito de comunicação pode ter seu sentido comum golpeado filosoficamente a partir da disseminação. Tal conceito corresponde a uma prática desconstrutora para vinculação - e, caso se queira, veiculação - dos múltiplos sentidos presentes - e também ausentes - de um texto. Nessa via, a disseminação desorganiza a unidade sólida e identitária de um sentido único e enclausurado, viabilizando a compreensão dos signos enquanto um encadeamento de significantes adiados (cf. Derrida, 1973) e, portanto, como rastros ausentes de significação unitária.

Assim, Derrida (1972) apresenta-nos a estrutura presente em torno do termo comunicação e de como esta é comumente retida. A partir daí, o autor fornece uma operação não essencializante para os movimentos em torno do que se queira enquanto comunicação. Contudo, precisamos partir, primeiramente, daquilo que entendemos com Saussure (2006): toda a questão que envolve o sistema linguístico propõe uma tradição que edifica a estruturação fechada do signo. Os resultados genealogicamente estabelecidos por Saussure, por meio de uma necessidade interna, exigem do significado a representação de uma imagem cujo encadeamento, obrigatoriamente, estabelece as relações com o fora, por meio daquilo que é tido enquanto significante, e toda a questão do signo é, no final das contas, uma designação na qual os acidentes externos da linguagem afetam o sistema interno dessa mesma língua. Dessa maneira, o que Saussure estabelece é um sentido imediato ao caráter dado pelo anúncio de algo.

Ou seja, com Derrida (1991), entendemos que a autoridade originária do signo corresponde às exigências clássicas de um pressuposto metafísico e presente. Porém, os efeitos constituídos nessa produção originária em torno do próprio signo operam uma cisão, na qual o reenvio de um núcleo infinitivo e ativo do diferimento forja toda a diferença a partir de um rastro de sentido presente no significante. Quando este signo representa a coisa em si - uma coisa em si dada em uma temporalização presente -, ele solicita o subterfúgio ativo daquilo que tenta representar: a coisa em si, de um ente-presente, pois exige uma presença diferida, posto que aquilo que é significado, faz-se significante a partir de um ente-não-presente. Assim, toda a diferença ressoa não apenas um movimento do significado, mas uma certa forma de 
movência, na qual "o simples fato de mover, de se mover ou ser movido" (Derrida, 1991, p. 40) investe em uma mediação de entre: a indecidibilidade entre todo o ativo e todo o passivo que se deixa designar pela própria diferença de sentido. A comunicação, portanto, é aqui operada enquanto termo que busca, justamente, o espaçamento desta diferença dada no interior metafísico do signo e que, por sua vez, constitui-se na união entre o significado e o significante.

Ainda, a partir de uma perspectiva não essencialista, entendemos que 0 ato de comunicar não diz respeito apenas ao transporte de uma proposição, tal qual fora inicialmente cogitada, mas diz daquilo que se quer. Isto é, a dispersão presente entre aquilo que se comunica de uma pessoa à outra, de um sujeito ao objeto, de um significado a um significante compreende um espaçamento no qual é possível tudo se dizer. É, portanto, justamente no interior, tanto quanto no exterior, dado entre os rastros, os espaçamentos e os desvios das forças ativas, reativas e médias de um signo que se faz possível tudo se querer-dizer (vouloir-dire). A comunicação, assim, quer-dizer de uma dispersão dada entre o interlocutor e o locutor, entre o remetente e o destinatário, entre o significado e o significante.

Podemos dizer que, em Derrida, que toda linguagem, como toda escrita, em qualquer sistema de signos, inclusive a fala, o emissor, seja o falante, autor, escriturador, perde seu sentido de origem. No livro Gramatologia (p. 104), o filósofo francês se refere ao termo programa (pois tem no horizonte os dispositivos cibernéticos) como o resultado de uma composição, em tese, da relação convencional entre significante-significado. Um programa de computador, por exemplo, ou um programa de TV, como composições que desejam uma programática linear direta entre mensageiromensagem, programador-programa. Ora, sua posição será sustentada na compreensão de que um significado é, acima de tudo, outro significante. Deste modo, apenas artificialmente, pode-se recuperar uma fonte, uma origem. Para Derrida (1973), o contexto original foi esvaído: restam, apenas, traços. Qualquer grafema é um traço cortado de sua pretensa origem. O destinatário, feito em destinerrance, poderá lê-lo, vê-lo, ouvi-lo enxertando sua própria letra, som, palavra. Não haverá uma experiência pura de significado, como afirma Nietzsche, só haverá interpretações (cf. 7 [60], 2013).

A relação entre diferentes suportes e inúmeros modos que permitem o processo de individuação estabelecidos a partir de movimentos da comunicação fazem pensar as oficinas enquanto uma aproximação teórica-metodológica com um ou mais atos educativos. Tal demanda permite questionar as oficinas desde sua estruturação. Nesta via, a fim de um encontro conceitual em torno da proposta estabelecida com a desconstrução derridiana, entende-se que Sandra Corazza fornece algumas outras invenções produtivas para o desdobramentos deste tema. Com Corazza (2011), as Oficinas de Escrileitura fornecem um andaime multivalente em torno do leitor, cuja coautoria comunica diretamente a relação dada com o texto escrito, valendo-se, ainda, 
de um compêndio de potencias que favorecem a extensão de um texto escrito pelo leitor enquanto reescrevível do texto original e, portanto, enquanto uma movência comunicativa pelas expressões vividas, sentidas e inventadas nas fruições e fantasias da experiência.

Se, com Corazza (2011), tais Oficinas de Escrileitura correspondem a uma escrita e leitura advinda dos modos biografemáticos propostos por Roland Barthes (1979), ou seja, uma contração entre aquilo que se entende por escrita tanto quanto aquilo que se compreende por leitura, entendemos que é a partir da desocupação de alguns territórios comuns da linguagem que se convocam cenas de violência que ultrapassam a natureza empírica, e mesmo teórica, de simples abertura de sentido. Se tais Oficinas de Transcriação (OsT) surgiram daquilo que fora conceituada por Corazza (2011) das proposições de problemas em cena, encontramos em Barthes (1979) um primeiro fragmento que evidencia a reivindicação em que um filme possa servir de território que recusa e excede todas as procuras daquilo que a comunicação comum deseja.

Para falarmos em assistir é necessário, pelo menos implicitamente, definir o que poderia ser uma cena daquilo que é assistido: "o artefato que permite criar, isolar, designar um espaço específico, que escapa às leis do espaço cotidiano, para pôr em lugar outras leis" (Aumont, 2008, p. 12). Com Aumont (2006), a encenação, ainda que raiz de uma representação teatral, expressa-se em toda a arte cinematográfica do imaginável constituindo o cinema enquanto um espaço no qual exprimem-se a filmagem de corpos que representam, sentem e vivenciam em um espaço e tempo determinados. Contudo, o autor reitera que os limites diante da autonomia contrários a arbitrariedade do ponto de vista de uma câmera enquanto objeto estático de apanágio de concepção obrigatoriamente expressiva, permitem ao contemporâneo que esta mesma câmera opere narrativas fragmentadas e elipsadas que fornecem ao espectador uma sensação - e não mais uma encenação.

Tal sensação permite uma prefiguração na qual as elipses presentes no plano sequencial da narrativa deixam de assinalar a duração estável da história, em uma encenação que dispõe o plano enquanto pormenor, mas impera as relações espaçotemporais entre os personagens e entre os próprios planos (cf. Aumont, 2006). Isto é, o drama deixa de ser maximizado enquanto elemento primordial do filme, cedendo lugar às intensidades particulares de cada registro, pois viabilizam os lugares não construídos, as cenas não enunciadas, os saberes não instituídos, as organizações de pensamento não articuladas diretamente pela câmera: abre-se o drama às cenas que permitem a disseminação da espectatura. Um cinema que permite ao espectador interagir na e com as imagens instituídas no espaço imperceptível daquilo que se assiste. rAssim, o espectador adere a um ato de espectatura que opera todo o filme enquanto uma permissão de conceito, pois este o constitui no plano daquilo que assiste, bem como constitui-se nos pormenores daquilo que comunica os sentidos que queira solicitar. Quer dizer, ainda que Aumont (2006) tenha optado pela não utilização 
de expressões que designam um vocabulário da imagem (estilo, representação), tanto quanto tenha se distanciado do vocabulário da narração (lógica, economia), entendemos que a partir do momento em que as OfiCines (OCi) solicitam ao espectador uma contribuição, os signos se dispersam e as separações latentes entre imagem e narração misturam-se à escritura.

\section{UMA INVESTIGAÇÃO OTOBIOGRÁFICA}

Esta pesquisa parte de uma investigação otobiográfica para dar conta dos textos produzidos no contexto das OCi. Investigar otobiograficamente é analisar as inscrições de um texto, qualquer que seja sua proveniência ou a suposta densidade de seu conteúdo, a partir da vinculação entre as vivências e o escriturado. Conceito advindo de obra homônima de Derrida (1984), a otobiografia funciona como um procedimento que se propõe a movimentar o bios de uma questão, como quisera Corazza (2014) ao guiar o método biografemático enquanto um método que se propõe a investigar a própria linguagem enquanto objeto. Este método elaborado por Corazza integra uma tipologia dos prazeres, cuja imagem de leitura permite uma relação leitor-escritor que, decididamente, efetiva o errático, as vidas, a vacilação do tempo e adota procedimento de desvios. Se este fora um dos métodos empregados enquanto parte das OsT, os espaços vazios ocupados pelas OCi buscam compreender a espectralidade das formas que engendram um filme tal como conceito, inventado a partir daqueles que escrituram e, portanto, a partir da bios que é movência no ato de espectatura.

Com Derrida (1984), a otobiografia dá vivência ao texto. Em um seminário a fim de criar metáforas que tornam um texto nietzschiano auscutável, o filósofo propõe-se a ouvir a produção formativa escrita de Nietzsche. Quando, portanto, os ouvidos são colocados em questão, a escuta desvela o que é próprio da formação deste ouvido: anatomicamente, o ouvido se aproxima de uma forma labiríntica e, não sem propósito, um labirinto, necessariamente, dá equilíbrio ao corpo que o produz. Quer dizer, os sintomas presentes em uma investigação otobiográfica tratam o bios enquanto um labirinto laudatório de inscrição. Ainda que esta demanda pareça destinar a uma produção escrita que presentifica a biologização de um texto, Derrida propõe, justamente, um contrário a isto, mesmo que não negue esta via. Os processos efetivados desta vida partem da sua constituição em vivências, e pelo fato destas jamais poderem ser singulares, o próprio processo da vida é vitae: curriculum cujas vivências auscutáveis compõem textos. Esta investigação otobiográfica subverte os espaços ocupados, contradiz as implicações estruturadas para uma espécie daquilo que implica estilos ao texto na força das afeições que são apreendidas: uma pesquisa que se queira otobiográfica não opera espaços de produção como espaços de coleta de dados. Uma pesquisa otobiográfica "recolhe e espalha: emprega, mesmo sob a pena da contrafanação, conceitos já fabricados, experimentando-os em outros espaços" (Monteiro, 2007, p. 483). 
A relação não convencional estabelecida por Derrida (1973) entre o grafema e o fonema ganham reconhecimento nesta pesquisa. Como dito anteriormente, no momento em que Derrida estabelece outra lógica, ou uma gramato-lógica para tratar da questão do signo, cunha a designação de um puro significante (grafema) fundado anteriormente à relação do significante-significado-significante (fonema). Nesta via, com Derrida (1998), o que designa uma ecografia parece ser aquilo que decifra a lógica do espectral. Isto é, na ocasião de os espíritos serem da ordem das vivências e, portanto, não puderem jamais ser singulares, no momento em que se fala do espírito, evocam-se "os espíritos, os espectros e quem herda escolhe um espírito antes do outro" (Derrida, 1998, p. 40). A essas expressões que podem mostrar imagens e sons, público ou privadas, reais ou virtuais, o material que se copia, acumula, ordena e classifica é distribuído por meio da enorme questão que envolve o signo. Assim, parece que Derrida nos propõe a questionar a imagem (significante) e o som (significado) dos fonemas de um sentido que deixa rastros de gravação, rastros de um arquivo invisível sob determinada superfície do grafema (significante puro). Assim, a investigação aqui proposta busca movimentar os conceitos abaixo indicados a partir dos procedimentos operados nas $\mathrm{OCi}$, por aquilo que se torna auscutável no texto, como ecografias que suplementam a constituição dos textos, das espectaturas, das escrituras e dos autores.

\subsection{Trace}

Com Derrida (2002) compreendemos que a ordem do traço amarra a letra ao corpo da cor, pois estabelece um testemunho das faixas que cortam e eclipsam uma narrativa: uma espécie de silêncio da morte que retrata em toda a palavra uma lição manifesta que cultiva uma imagem, ainda que esta seja uma imagem de cor, de semelhança ou figurativa: o corpo não se ausenta no traço, mas violenta a inegável virtude de estar presente no próprio corpo envolvido no ato de espectaturar, por exemplo. Todas essas experiências em torno daquilo que se quer com a espectatura contra-assinam o próprio corpo na medida em que a presença não bem-sucedida do ser em algum lugar se reúne ao próprio espaço das OCi.

Neste caso, as experiências propostas nas OCi acontecem naquilo que resta o à despeito das aparências dos envolvidos: a obra em questão é aquilo que resta, resto, rastro [trace], traço. Isto é, o cinema, ou mesmo a relação cinética, é uma questão de traço: como lidamos com imagens em movência na constituição cinematográfica, toda a obra é assinada e contra-assinada lidando com os imperativos que as atravessam: atores, diretores, espectadores e máquinas são os corpos que permanecem e restam aos efeitos dos atos discursivos de uma única e óbvia assinatura. No entanto, na ausência de um corpo equivalente ao estar ali edificado, em que demonstre-se de antemão a pronunciada verdade de um nome que funciona como signo linguistico e corpo identitário, os elementos do dentro e fora desta assinatura cedem ao traço um espaço privilegiado, tanto quanto complicado. Ora, se o traço é o primeiro manifesto 
de uma composição fílmica ao identificar que um objeto em movência acontece com forças externas e internas às performatividades de uma obra, posto que tudo é questão de rastro, cada presente é estruturado com remissão à outra coisa. A experiência das OCi assume a performatividade do rastro ao não lidar com a presença do sentido, mas, tão somente, com ecos, como uma ecografia.

\subsection{Graphème}

Um segundo conceito estruturante é o de graphème (cf. Derrida, 1973). Com este conceito, desloca-se os signos de seu enclausuramento histórico-metafísico. Entre a tensão do gesto e do propósito estabelecidos na unidade do significante a uma instância irredutível de sua essência como outra unidade da phoné, o grafema ganha reconhecimento enquanto corpo primeiro, tal qual fundante da constituição do primeiro rastro da escritura. Contudo, se tal designação suporia uma origem das coisas, Derrida toma os grafemas como um assunto em torno das grafias que reapropriam questões de ritmo e estilo da situações viventes, cuja condução torna possível ler os grafemas como aquilo que, a partir de um modo de ressonâncias da fantasmagoria própria do rastro e de seus recursos, criam movimentos de apropriação em torno do puro significante. Neste embate, adia-se o campo da história de um movimento que é tele: guiado, visionado, experenciado em torno do que grafa uma outra lógica. Se este significante puro é o que remete a uma medida primeira do rastro, ainda que sem sua origem edificadora, o grafema é outra medida daqueles que predizem, assinam, assinalam, citam e enviam os presságios em mais de um idioma, por meio de uma escritura que restitui uma caligrafia não representativa, mas, sim, uma excedência do significante.

\subsection{Phonème}

O phonèma, para Derrida (1973), é aquilo que articula o som e o sentido da fonia. Levando em consideração que para as perspectivas fonocêntricas a escritura seria sempre derivada, representativa e fonética, entendemos que para declarar um efeito, cuja escritura ganhe reconhecimento de escritura enquanto tal, e não mais tal qual instrumento subordinado. É necessário compreender os ecos que compõe os espaçamentos entre o dito significado-significante-significado. Ao admitir que a unidade imediata e privilegiada que fundamenta a significância e o ato de linguagem é a unidade articulada do som e do sentido na fonia, podemos estabelecer mais: se os ecos de uma tele correspondem também ao traço destas grafias que impõe uma imagem não imediata, mas reinscrevem o timbre da voz, da imagem e da própria espectatura, entendemos que os textos produzidos são entendidos como insurgentes, portanto, não literais. 


\section{OFICINES DE ECOGRAFIA}

A empiria praticada com as OCi fora realizada em duas escolas do município de Cuiabá e, como dito anteriormente, contaram com o mesmo procedimento em dois espaços escolares formais baseados em diferentes orientações: o primeiro, fora uma escola pública; o segundo, em uma escola privada confessional. Ainda que as OCi tenham repetido as adoções tomadas em ambos os espaços, com duração de uma hora e trinta minutos, cujos os participantes somaram noventa e cinco estudantes, sendo destes, trinta e oito da primeira escola e cinquenta e sete da segunda, as produções contrafanaram diferentes manifestações: alguns textos escreveram nas margens; outros, doaram-se em branco. Todos os textos, em suas potências escrituradas em tinta ou na ausência de suas grafias foram consideradas como ecos do procedimento proposto. Ademais, a grafia proposta em cada texto fora mantida a fim de figurar, exceder e criar sentido nos assentamentos que responsabilizam a linguagem dos grafos.

Para o procedimento das $\mathrm{OCi}$, fora selecionado quatro curta-metragens que propunham reduzir as fronteiras dos sons, dos movimentos, dos gestos e das potências que se desdobram na superfície das imagens acumuladas. Os quatro curtametragens exibidos foram subsequenciados em: Alike (2015), Linear (2012), The Maker (2010) e Paradoxo da espera do ônibus (2007). Ainda que o plano sequencial pareça demonstrar, superficialmente, um drama narrado enquanto objeto fílmico, tais curtas criam espaços de significação em espectatura com quem os assiste. Estes curtas, disponíveis em plataformas online, intensificam narrativas fragmentadas pelas elipses do plano sequencial, pois misturam som e imagem em uma perspectiva sentidos em adiamento.

As OCi foram organizadas da seguinte maneira: a) os curtos foram apresentados aos estudantes dada a ordem supracitada; b) ao final de cada curta, os participantes dispunham de um total de dez minutos para escriturar aquilo que fora afetado, sentido, deslocado, proporcionado e pensado no momento do assistido; c) para a escritura, fora distribuída uma folha para cada participante, cujas indicações contavam com o título do projeto, título do curta em questão e um quadro abaixo: ao lado esquerdo, um espaço em branco para aquilo que denominamos "Nome fictício", ao lado, dezessete linhas para aquilo que chamamos de "Texto"; d) as folhas escrituradas eram devolvidas aos oficineiros responsáveis; e) novas folhas eram redistribuídas para a repetição do processo nos quatro curta-metragens; f) por fim, ao término da quarta e última escritura, fora aberto um espaço para discussão direta com os participantes, a fim de convidar aqueles que quisessem dizer algo a partir do espectaturado.

Dentre os trezentos e cinquenta e sete textos contabilizados ao final de ambas as OfiCines, selecionamos oitenta e oito textos escritos a partir do curta-metragem Alike (2015). Sua sinopse descreve uma vida agitada de um pai que tenta ensinar a seu filho um caminho correto. Embora o curta-metragem ofereça fácil identificação 
narrativa, os diretores Martinéz e Méndez apresentam aspectos que são preponderantes, além de elementos plásticos e visuais não centrais para identificação de um único e possível caminho correto. Dessa maneira, a necessidade latente de cada cena reconstitui cuidados e sentidos históricos, mas viabiliza facilmente uma comunicação que não se queira apenas encenação, e sim sensação (cf. Aumont, 2008). A escolha deste curta, com uma narrativa mais evidente, acaba por apelar pelo sentido mais imediato dado pelo estudante diante de uma folha que solicita a marca da tinta, vindo a dirigir-se a uma corrente intimista, um espetáculo ocular ou, melhor, a um espetáculo auricular.

\section{NÓMOS DADOS-A-PENSAR}

A investigação otobiográfica, valendo-se das OfiCines de Ecografia (OCiE), estabelece três leis de análise dos textos produzidos em seu contexto; foram chamadas de nómos: a) Heteronomia do Estado (analítica que toma os parâmetros do estado para a estrutura textual), b) Autonomia Crítica (compreensão dos elementos oriundos do próprio participante para dar composição, latência e sentido ao texto produzido), e c) Economia dos Signos (cuja manifestação encontra nos espaçamentos da escritura uma convocação dos pleiteantes ao contra-tempo do discurso, assumindo o texto como corpo). Tais leis somam espírito, letra, palavra falada ou escrita ao traço da cor, da vida e da morte: as leis tomam o outro, o si mesmo e a escritura como um caso de oferecer respostas aos movimentos presentes no espectral que cunham os ouvidos da educação.

\subsection{Heteronomia do Estado}

As oitenta e oito escrituras elaboradas a partir do curta Alike (2015) foram analisadas por professoras de língua portuguesa que possuem experiência em avaliação de redações do Exame Nacional do Ensino Médio (ENEM/MEC/BRASIL), valendo-se dos critérios usados pelo Instituto Nacional de Estudos Pedagógicos Anísio Teixeira (INEP). Estas normas foram sintetizadas em três critérios, a saber: 1) a qualidade da elaboração dos enunciados escritos pelos estudantes; 2) o uso adequado da norma culta na escrita; 3 ) a consistência da coerência textual. Cada enunciado recebeu uma nota de 0 à 5 (sendo 0 muito fraco, e 5 muito bom). Ao final, fora calculado as médias gerais dos participantes de ambas as escolas e sublinhadas a maior e a menor nota de cada. A média geral das duas escolas fora: 3,7 pontos da escola privada confessional e 3,0 da escola pública. Ainda, a maior pontuação obtida na escola pública fora 4,3 pontos e, na escola privada, 5,0. Ambas as escolas obtiveram a menor pontuação em 2,0. Nota-se que o menor desempenho atingido igualmente por ambas as escolas reitera uma diferença sútil entre as configurações educacionais de cada instituição, posto que fora notável tal diferença apenas em relação ao desempenho superior e médio, 
Ainda que não tenhamos propriedade para falar do corpo administrativo, do corpo discente e do corpo docente das instituições nas quais as OCiE foram realizadas, entendemos que não se trata apenas de jogar com as solidariedades eminentes. A diferença de $14 \%$ dos pontos entre o público e privado unem uma espécie de hipotético que poderia ter função no combate do Estado no horizonte da ciência. Isto é, não se quer apenas postular a homogeneidade dos corpos unidos ou desunidos em uma luta em torno da equitação do discurso. Contudo, como estabelecemos os parâmetros nacionais de avaliação para a pontuação destes textos, entendemos que é evidente e mereceria, talvez, uma crítica em combate ao responsável que compromete as proposições apresentadas. Esta diferença não é aquilo que entendemos enquanto o próprio impossível cunhado pela filosofia derridiana, mas um signo estranhamente familiar de que há certa culpabilidade que compromete a questão do coletivo, ainda que "uma tal problemática nem sempre se reduz, e às vezes em absoluto já não se reduz, a uma problemática política centrada no Estado" (Derrida, 1999, p. 139), mas em formas aparentemente inter ou transestatais que comprometem as estruturas estatais e as finalidades da organização sistemática.

Tais questões que tomam a abstração, por vezes epistemológica, do interior das estruturas - o que inclui também o sistema arquitetônico, a fundação das organizações e as tradições e afins acidentais - definem certa razão que orienta empiricamente as funções refenciais e variáveis que contextualizaram as OCiE. Com Derrida (2007), entendemos que a lei da heteronomia, ao cunhar a relação com o outro, implica na responsabilidade que pertence ao sistema das forças que escapam e nem poderiam ser controladas, contudo, precisam comprometer um envolvimento em torno das palavras, do termos e dos conceitos que parecem ter função de vontade e soberania daquilo que deveria ser, aparentemente, democrático. Nesta via, esta lei entende que é preciso investir na responsabilidade que questiona o contato com o outro - não necessariamente sujeito, mas corpo igualmente sabido, pois busca desconstruir a conjuntura do signo apreendido em sua forma (significante) e reprodutibilidade estável.

\subsection{Autonomia Crítica}

A fim de contabilizar o conteúdo que fora produzido nos textos das OCiE, partimos do que Freire (2011) estabelece como autonomia. A partir da investigação, computou-se a maior recorrência dos termos utilizados pelos participantes, sendo "pai" e "filho" os mais frequentes nas escrituras de ambas as escolas. Porém, na escola privada, os participantes grafaram sessenta e oito vezes o termo "pai", enquanto na escola pública, o termo "filho" fora o mais assíduo, aparecendo vinte e oito vezes. Assim, os textos de Buildyuudy (nome fictício escolhido pelo participante da OCiE da escola privada) e Arjoma $\mathrm{H}$. Orez (nome fictício escolhido pelo participante da OCiE da escola pública) foram selecionados para demonstrar tal analítica. 
Buildyuudy escritura a partir de Alike (2015) um movimento que parece assumir autonomia em relação à figura do pater (pai, partido, patriarcado, patrão, estado: o outro identificado). A escritura fala do medo da absoluta identificação, sem crítica, de uma ordem instituída. Lamenta a ausência de um discurso em torno da e na escola. Ainda, Buildyuudy supõe um lugar no qual compreende sua presença em sociedade, porém a questiona e clama por uma discussão em torno do que é aparentemente negado. Arjoma H. Orez quer autonomia. Contudo, em movimento diferente do apresentado por Buildyuudy. Orez não se preocupa com a vida tal como ela é: repleta pela rotina do pai e ausente pela rotina do filho. Orez aceita a repetição na sua vida e entende que ela pode diferir; escritura, a partir de um si instituído, as possibilidades de seus instintos: indaga não ter tudo, feito Fausto, sob pena de Goethe, diante de Mefistófeles, dirigente dos destinos da terra. "Porque não posso ter os dois?". O que Orez propõe não toma como questão o receio de se tornar o outro-preso-à-rotina, o outro: quer liberdade de dizer sim, ao som do martelo de Nietzsche. Eis as escrituras, respectivamente:

É um texto que mexe com todos na sala, uma vez que muitos de nós, temos o medo de nos tornarmos como o pai. Muitas vezes nos pegamos pensando em como era bom ser criança, ou odiando nossa rotina e ao ver esse curta nos relacionamos, infelizmente, ao pai. Acho que é uma ótima reflexão e um momento em que podemos parar para pensar o que pode ser feito para que continuemos sempre como a criança ou "coloridos" e também acho que assuntos como esse (não cair na rotina, procurar a felicidade, ser autêntico) deveriam ser abordados mais frequentemente em sala - Buildyuudy, OCiE, 2018.

O que é melhor para mim? Num mundo onde eu vivo, devo ser igual aos outros para me juntar a sociedade ou seguir os meus instintos, ser feliz? Quem eu realmente sou? Porque não posso ter os dois?

Com Derrida (1973), entendemos que relação topológica a partir dos termos que empregam as filiações e genealogias assinam uma vontade de autonomia em relação tropológica as forças escrituradas. Isto é, a autonomia dos participantes é reiterada a partir de figuras que Ihes pareçam enquanto maximizações de suas próprias vontades e o medo é aquilo que é próprio do topológico, ainda que seja dado a partir de uma relação tropológica: "o medo não tem contrário, ele é coextensivo a todo o campo das paixões [...] e o medo é de início o medo do próprio corpo, pelo corpo próprio, pelo seu próprio corpo, ou seja, pela vida. A vida tem medo" (Derrida, 2016, p. 72-73). Assim, a relação estabelecida por medo do que espectatura estabelece uma escritura que corrobora o vivente com um medo que é seu, diante daquilo que constitui a si mesmo, pois a topologia da escritura forja tropologicamente a autonomia de corpos que estão se constituindo: o outro e o eu, o conteúdo (significado) do signo que baliza a estrutura latente. 


\subsection{Economia dos Signos}

Esta última e terceira lei estabelecida discorre acerca da casa ocupada pelo signo. Com Heidegger (2000), uma das questões da linguagem gira em torno desta estar ocupada pela casa do ser. Isto é, a linguagem torna-se morada do ser. Assim, Heidegger (1988) cunha o Dasein, tal qual parte do ser, ainda que não seja seu presente, nem aquilo que o constitui, mas a possibilidade de descrevê-lo. Quer dizer, o Dasein é ao mesmo tempo aberto pelo ser tanto quanto é a sua abertura. A fim de evitar uma expressão que indicaria uma tradução daquilo que o ser é, Heidegger afirma que o ser acontece, pois ele se dá (Ereignet). Nesse sentido, preserva a nuance entre o próprio ser e o seu vivido, rompendo com a objetividade do ser, pois este é visto enquanto um ato genérico e sem substancialidade, executor de uma manifestação verbal e descritiva de ser acontecendo no tecido linguístico, no qual o seu gerúndio demanda a sua vivência: ainda que não escolha sua abertura, esta pertence ao ser, e a sua necessidade de abertura para os entes manifesta o próprio ente como pertencimento desse Dasein à abertura que constitui o Ereignet.

Ao radicalizar a intuição parmênidica, Heidegger (2000) introduz um elemento perturbador ao pensamento, pois cede o lugar das preocupações em torno das instituições propriamente humanas para abrigar um tecido linguístico. Diante deste tecido linguístico, Derrida (2009) propõe que "quando o escrito está defunto como signo-sinal que nasce a linguagem" (Derrida, 2009, p. 15). Deste modo, o que Derrida (2007) reitera é que o jogo do triângulo linguístico deixa de ser de um signo ao outro para remeter-se ao si mesmo, a um signo ausente de sua significação, cuja a escritura suspende o movimento utilitário. Ainda que esta mesma escritura permaneça ocupada pelo transporte da informação, enquanto uma experiência e um rumo a sua destinação, destina-se constantemente em errância, em destinerrância [destinerrance], pois cria a oferta de sentido, dissemina a comunicação comum e (con)signa afetos imanentes daquilo que é próprio do texto, do querer-escriturar, do acontecimento da escritura enquanto tal: um espaçamento no qual os signos se tornam.

Para demonstrar essa posição assumida neste texto, escolhemos um participante que escriturou a partir dos quatro curtas espectaturados. Com nome fictício $E u$, o autor escriturou em cada curta, na ordem da exibição: "não sei o que estou fazendo aqui"; "ainda não sei o que estou fazendo aqui"; "hoje me dei conta que é primavera"; "digam à menina de azul que gostaria de beijá-la". "Eu" brinca com o jogo dos signos, comunica que a casa deste jogo não deve economizar o seu querer-dizer. Este escrito-defunto como signo-sinal nasce como linguagem ao consignar afetos, pois "deixar a palavra ao furtivo é tranquilizar-se na différance, isto é, na economia" (Derrida, 2009, p. 281). Quer dizer, "Eu" clama em seu não-nome a presença de um não-presente em si, de uma espectatura que descola o significante do significado e dissemina o texto em sua manifestação mais especulável: o texto dissemina o si 
mesmo e outro em uma conjecturação de destinerrâncias. Resta saber a quem fora destinado os seus traços, a quem fora ecografado suas afecções e de onde adveio a poética de seus grafos. Ou, melhor: tudo isto é questão de rastro.

\section{ALGUMAS CONSIDERAÇÕES}

Compreendemos que as OfiCines de Ecografia criaram sentidos a partir do espectaturado. Como é relevante das relações de afetação que nem todos sintomatizem em uma via homogênea as infinidades de um caso, pudemos dizer, com Aumont (1992), que a imagem fora produto tanto quanto fora movida no momento destas relações de afetação. Assim, uma relação criada entre o dentro e o fora da imagem, do texto e do si mesmo constituíram atos de aprendizado. Tais atos solicitaram aos filmes, ao momento e aos participantes que acionassem tudo aquilo que lhes coubesse a fim de inventar, fabular e ponderar sobre os curtas assistidos: neste tempo, neste recorte, os filmes foram tomados pelos próprios participantes como conceito, ainda que acidentais.

Os procedimentos foram desenvolvidos a partir daquilo que definimos enquanto echographie. O termo empregado constitui a contração de neologismos cunhados por Derrida em torno dos rastros presentes no invisível: trace (Derrida, 2002), graphème e phonème (Derrida, 1973). Se a investigação otobiográfica buscara desafiar as coletas, os litígios dos dados em dispersão, o contratempo, dando-se desde as bordas, desde seu para além sem para além da palavra falada ou escrita, do traço e da cor, da imagem deserarquizada do signo, do sentido e da forma do significante, a ecografia oferece um triângulo sem-pose e sem-repouso. Assim, despojados de tudo aquilo que representa um tempo sem desafios, optamos pelo contra-tempo das OCi: uma ecografia que desconstrói o triângulo linguístico de duas partes e encarraga-se de oferecer uma opção não dialética. Os participantes das $\mathrm{OCi}$, para além de toda a apódose, espectaturaram a pose e a oposição, mas no momento em que convidados a escriturar, rubricaram uma contra-assinatura de autoria na imagem dada a pensar e, na experiência da história da história, esta tese [thesis, nomos, setzung, gesetz] nos foi dada a criar: a lei como tema que não consiste em representar, ou mesmo apresentar, à luz da imagem, um espectral que poderia ser dito de outra maneira que não: sem-pose e sem-repouso (cf. Derrida, 2012).

Os três nómos dados-a-pensar fomentaram, também, uma discussão em torno da espectatura enquanto uma possibilidade para mobilizar os atos educativos: parece que, para todos eles, uma lei pedagógica vigorava a investigação. Talvez esta lei pedagógica seja o caminho da lei que faz de uma oficina o desenvolvimento de um conjunto de afetações com auxílio das e nas vivências enquanto o próprio ato educacional. Uma possibilidade de pensar o que se quer quando diz sem-pose e semrepouso para o assistido e para os espectadores. Quer dizer, entendemos, com Derrida (1991), que toda a questão é autobiográfica, e por sê-la, envolve vida e morte em processo único, disperso e comunicável.

Ámbitos. Revista Internacional de Comunicación | ISSN: 1139-1979 | E-ISSN: 1988-5733, №. 49. (2020) 


\section{Notas}

1 Este trabalho contou com a participação de bolsistas de Iniciação Científica da Universidade Federal de Mato Grosso; são eles: Iris Clemente de Oliveira Bellato (http://lattes.cnpq.br/4018120581669988), Louise Gomes de Pinho (http://lattes.cnpq.br/5812615840678634), Mateus Moraes de Oliveira (http://lattes.cnpq.br/9343301278452146) e Matheus Bassan Alvino Brombim Lopes (http://lattes.cnpq.br/0911734042003411).

2 Agamben tratará a questão do nómos enquanto um campo do biopolítico na modernidade. Ao estabelecer uma genealogia dos governos e políticas, o autor conceitua o nómos em torno de biopolítico secreto que diagnostica uma crítica da realidade em seus aspectos estruturantes sobre o nexo existente entre poder político e vida nua. Tal contribuição da racionalidade política não será questão deste trabalho. Ver mais em AGAMBEN, G. (2010). Homo Sacer: poder soberano e vida nua I (H. Burgo, Trad.). Belo Horizonte: Editora UFMG.

\section{Referências}

Aumont, J. (1992) La imagen. (Antonio Lopez Ruiz, Trad.) Barcelona: Paidós Comunicación. . (2006). Le cinéma et la mise en scène. Paris: Armand Colin. . (2008). Pode um filme ser um ato de teoria?. Educação \& Realidade, 33, 21-34.

Barthes, R. (1979). Sade, Fourier, Loiola. (Maria de Santa Cruz, Trad.) Lisboa: Edições 70. . (2004). O rumor da língua. (M. Laranjeira, Trad.). 2 ed. São Paulo: Martins Fontes.

Corazza, S. M. (2011). Caóides. In: MONTEIRO, Silas (Org.) (Coleção Escrileituras). Caderno de Notas 2: rastros de escrileituras. Canela: Ed. UFRGS, 13-17. . (2014). Introdução ao método biografemático. Em tese, 20, 3, set/dez, 48-65.

Derrida, J. (1972). La Dissémination. Paris: Éditions du Seuil. . (1973). Gramatologia. (Miriam Schnaiderman \& Renato Janini Ribeiro, Trad.). São Paulo: Perspectiva.

. (1984). Otobiographies: l'enseignement de Nietzsche et la politique dun nom propre. Paris: Galilée.

. (1991). Margens da filosofia. (J. Torres Costa, A. M. Magalhães, Trad.). Campinas: Papirus.

. (1998). Ecografías de la televisión. (M. Horacio Pons, Trad.). Buenos Aires: Editorial Universitaria de Buenos Aires.

(1999). O olho da universidade. (Ignacio Antonio Neis \& Ricardo luri Canko, Trad.). 
São Paulo: Estação Liberdade.

(2002). Trace et archive, image et art. Paris: INA Éditions.

(2007). O cartão-postal. (Simone Perelson \& Ana Valéria Lessa, Trad.). Rio de Janeiro: Civilização Brasileira.

. (2009) A escritura e a diferença. (M. Beatriz Marques Nizza da Silva, P. Leite Lopes \& P. Carvalho, Trad.). São Paulo: Perspectiva.

. (2012). Pensar em não ver: escritos sobre as artes do visível (Orgs.). (M. Jacques de Moraes, Trad.). (Ed. Rev.). Florianópolis: Editora da UFSC.

. (2016). A besta e o soberano (seminário). v. 1 (Marco Antônio Casa Nova, Trad.). Rio de Janeiro: Via Verita.

Freire, P. (2011). Pedagogia da autonomia. Saberes necessários à prática educativa. São Paulo: Paz e Terra.

Heidegger, M. (1988). Ser e Tempo (Parte I) 2. ed. (Márcia de Sá Cavalcanti, Trad.). Petrópolis, Vozes.

. (2000). Carta sobre el Humanismo (H. Cortés, A. Leyte, Trad.). Madrid: Alianza Editorial.

Monteiro, S. B. (2007). Otobiografia como escuta das vivências presentes nos escritos. Educação e Pesquisa. 33, 3, set/dez, 471-484.

Nietzsche, F. (2013). Fragmentos póstumos: 1887-1889 volume VI (Marco Antônio Casanova, Trad.). Rio de Janeiro: Forense Universitária.

Saussure, F. (2006). Curso de linguística geral. (Antônio Chelini, José Paulo Paes \& Izidoro Blikstein, Trad.). São Paulo: Cultrix.

\section{Filmografia principal}

Admoni, A. (2012). Linear. São Paulo: Estúdio Admoni. Filme.

Caseli, C. (2007). Paradoxo da espera do ônibus. Rio de Janeiro: Christian Casseli. Filme.

Kezelos, C; Kezelos, C. (2010). The Maker. Los Angeles: Zealous Creative. Filme.

Martínez Z, L; Méndez, R. C. (2015). Alike. Barcelona: Pepe School 
